\title{
Atriyal Fibrilasyon Tanısı Olan Hastalarda Obstrüktif Uyku Apnesi ve Uyku Kalitesinin Belirlenmesi
}

\author{
Şeyma Şengül, ${ }^{1} \oplus$ Hilal Uysal ${ }^{2}$
}

${ }^{1}$ American Hastanesi Vehbi Koç Vakfı, Sindirim Sistemi-Cerrahi Servisi, İstanbul, Turkey

2istanbul Üniversitesi-Cerrahpaşa Florence Nightingale Hemşirelik Fakültesi, İç Hastalıkları Hemşireliği Anabilim Dalı, İstanbul, Turkey

\begin{abstract}
Özet
Amaç: Araştırma, atriyal fibrilasyon tanısı olan hastalarda obstrüktif uyku apnesi ve uyku kalitesinin belirlenmesi amacıyla tanımlayııı bir çalışma olarak planlandı ve uygulandı.

Yöntemler: Araştırma, Aralık 2017 ile Mart 2018 tarihleri arasında, İstanbul'da iki üniversite hastanesinin kardiyoloji servislerine yatan, iletişim sorunu olmayan, hekim tarafından AF tanısı konulmuş olan, araştırmaya katılmayı kabul eden 108 hasta ile gerçekleştirildi. Araştırmada elde edilen veriler SPSS 22 software program (IBM Corp., Armonk, NY, USA) programı kullanılarak analiz edildi. Verilerin değerlendirilmesinde tanımlayıcı istatistiksel yöntemler, t-testi, Tek yönlü (One way) Anova testi kullanıldı.

Bulgular: Araştırmamıza katılan bireylerin \%47.2'sinin erkek, \%52.8'inin kadın olduğu, büyük çoğunluğunun 60 yaş ve üzerinde olduğu, yaş ortalamasının $68.99 \pm 14.02$, BKi ortalamasının $27.09 \pm 5.12 \mathrm{~kg} / \mathrm{m}^{2}$ olduğu belirlendi. Bireylerin \%73.1'i yeterince uyuduğu halde sabah yorgun uyandığı ve gündüz aşırı uykulu olduğu, \%82.4'ünde unutkanlık, sinirlilik ve dikkat azlığı olduğu, \%38'inin gece horladığı, \%39'unun yorgunsa horladığı, büyük çoğunluğunun (\%68.5) sabahları baş ağrısı şikayeti olduğu, \%69.4'ünün sabahları ağız kuruluğu ve boğaz ağrısı şikayeti olduğu belirlendi. Bireylerin uyku kalitesi puan ortalaması $11.315 \pm 3.370$ olarak tespit edildi. Yaş değişkeni arttıkça ve ve oksijen saturasyonu düzeyi azaldıkça uyku kalitesinin azaldığı belirlendi $(p=0.000)$. Sakinleştirici veya uyku hapı alan bireylerin uyku kalitelerinin kötüleştiği tespit edildi ( $\mathrm{p}=0.000)$.

Sonuç: AF tanısı olan hastaların uyku kalitesindeki azalma göz önüne alındığında bu konuda hemşire ve diğer sağlık personeli eğitilerek uyku kalitesini arttırmaya yönelik eğitim programlarının düzenlenmesi, bakım ve tedavi esnasında hastaların uyku kalitelerinin incelenmesi, gerekirse gece uygulanan tedavi planının uyku kalitesini bozmayacak şekilde düzenlenmesi önerilebilir.
\end{abstract}

Anahtar sözcükler: Risk faktörleri; uyku; uyku apne sendromu.

\section{Obstructive Sleep Apnea and Determination of Sleep Quality in Patients with Atrial} Fibrillation Diagnosis

\section{Abstract}

Objective: The study was planned and performed as a descriptive study in order to determine obstructive sleep apnea and sleep quality in patients with atrial fibrillation.

Methods: The study was conducted between December 2017 and March 2018 with 108 patients admitted to the cardiology services of two university hospitals in Istanbul, who had no communication problems, diagnosed as AF by the physician and

İletişim (Correspondence): Dr. Hilal Uysal. İstanbul Üniversitesi Cerrahpaşa Florence Nightingale Hemşirelik Fakültesi, İ̧ Hastalıkları Hemşireliği Anabilim Dalı, Abide-i Hürriyet Cad, Şişli, İstanbul

Telefon (Phone): +90 5358170616 E-Posta (E-mail): hilaluysal@gmail.com

Başvuru Tarihi (Submitted Date): 11.09.2019 Kabul Tarihi (Accepted Date): 16.09.2019

OCopyright 2019 by Turkish Society of Cardiology - Available online at www.anatoljcardiol.com 
accepted to participate in the study. The data obtained from the study were analyzed using SPSS 22 software program (IBM Corp., Armonk, NY, USA). Descriptive statistical methods, t test, One way Anova test were used to evaluate the data.

Results: It was determined that $47.2 \%$ of the participants were male, $52.8 \%$ were female, the majority were 60 years and older, the mean age was $68.99 \pm 14.02$, and the mean BMI was $27.09 \pm 5.12 \mathrm{~kg} / \mathrm{m}^{2} .73 .1 \%$ of the individuals were sufficiently sleepy, woke tired in the morning and were extremely sleepy during the day, $82.4 \%$ had forgetfulness, irritability and lack of attention, 38\% snored at night, 39\% snored if tired, and the majority (68.5\%) had mornings $69.4 \%$ had dry mouth and sore throat in the morning. Mean sleep quality score of the individuals was found to be $11.315 \pm 3.370$. It was determined that sleep quality decreased as age variable increased and oxygen saturation decreased $(p=0.000)$. The sleep quality of the sedatives or sleeping pills was deteriorated $(p=0.000)$.

Conclusion: Considering the decrease in the sleep quality of patients with $\mathrm{AF}$, it may be suggested to train nurses and other health personnel and to organize training programs to improve sleep quality, to examine the sleep quality of the patients during care and treatment, and to arrange the night treatment plan in a way that does not impair sleep quality.

Keywords: Sleep; sleep apnea syndromes; risk factors.

Cite this article as: Şengül \$̧, Uysal H. Obstructive Sleep Apnea and Determination of Sleep Quality in Patients with Atrial Fibrillation Diagnosis. Turk J Cardiovasc Nurs 2019;10(22):50-58.

A triyal fibrilasyon genel popülasyonda en sık rastlanan sürekli kardiyak aritmidir. ${ }^{[1]}$ Tüm yaşlarda prevalans erkeklerde kadınlardan daha fazla olmasına rağmen, $\mathrm{AF}^{\prime} \mathrm{li}$ kadınlar sayısal olarak daha fazladır. Framingham çalışmasında AF tanısı olan erkek-kadın oranı 1.7 olarak açıklanmaktadır. ${ }^{[2]}$ Altta yatan kardiyak sorunların dışında bile, her altı bireyden birinde yaşam boyu AF riski görülmektedir. AF gelişme riski 40 yaşına ulaşmış kişilerde yaklaşık $\% 25^{\prime}$ tir. [3] Yaşam boyu risk oranları, AF'nin halkı ne kadar önemli derecede tehdit ettiğini göstermekte olup, korunmaya ve tedavi planlanmasına ilişkin çalışmalara öncelik verilmesi gerektiğini vurgulamaktadır. ${ }^{[4,5]}$

Ülkemizde AF prevalansı ile ilgili veriler Türk Erişkinlerinde Kalp Hastalığı ve Risk Faktörleri (TEKHARF) çalışması ile gösterilmiştir. On yıl boyunca takip edilen 3450 bireyin katıldığı TEKHARF çalışmasında, AF'nin genel prevalansı $\% 1.25$ olarak bildirilirken, 32-59 yaş grubunda $\% 0.46,60-69$ yaş grubunda \%2.09, 70 yaş ve üzerinde ise $\% 2.49$ olarak bildirilmiştir. ${ }^{[6]}$ AF'li hastaların yaş ortalamasının 67 , kadın ve erkek oranının 1.69 olduğu belirtilmiştir. ${ }^{[7]}$ Ülkemizde yapılmış bir diğer çalışma olan Atrial Fibrillation in Turkey: Epidemiologic Registry (AFTER)'da ise, en yaygın görülen AF tipi non-valvuler AF (\%78) iken, kalıcl-ısrarlı AF'nin tüm hastaların \%81'inde görüldüğü bulunmuştur. AF tanısı olan hastaların \%60'ı kadın olarak tespit edilmiştir. ${ }^{[6]}$

Son yapılan çalışmalarda AF gelişiminden, kontrol edilemeyen risk faktörleri (yaş, genetik vb.) sorumlu olduğu kadar, kontrol edilebilen risk faktörlerinin de sorumlu olduğu vurgulanmaktadır. Obezite, Obstrüktif Uyku Apne Sendromu (OSAS), Hipertansiyon (HT), Diabetes Mellitus (DM), alkol tüketimi kontrol edilebilir AF risk faktörleri arasında gösterilmekte ve bu durumlar hakkında yaşam şekli değişikliklerinin önemi vurgulanmaktadır. Bu kontrol edilebilir risk faktörlerinin olumsuz etkisi uygun medikal tedavi ve yaşam şekli değişiklikleri ile azaltılabilir, dolayısıyla AF riski de en aza indirilebilir. AF riskini azaltmak için HT ve diyabetin kontrol altında tutulması, alkol tüketiminin günde iki kereden az olması, kilolu ise kilo vermesi, OSAS'ın tedavi edilmesi önemlidir. ${ }^{[8]}$ Genel olarak bakıldığında, bu yaşam şekli faktörlerinin düzenlenmesi ve değiştirilmesi için doğru beslenme ve uyku kalitesinin iyileştirilmesi öncelikli ele alınması gereken durumlardır. Gelişmiş ve gelişmekte olan ülkelerde, $A F$ ve beslenme durumundaki anormallikler bugünkü sağlık bakım sistemindeki en yaygın zorluklardandır. ${ }^{[9]}$

Obstrüktif uyku apne sendromu, uyku ile ilişkili solunum bozuklukları başlığı altında incelenen, toplumda çok sık görülen, HT, Kalp Yetersizliği (KY), pulmoner hipertansiyon gibi birçok kardiyovasküler hastalığın (KVH) etiyopatogenezinde ve ilerlemesinde rol oynayan, tıbbi açıdan tedavisi zorunlu olan, yüksek morbidite ve mortaliteye yol açabilen bir hastalıktır. ${ }^{[10]}$ OSAS, hem AF'nin gelişmesinde hem de kateter ablasyon sonrasında ilişkili bir risk faktörü olarak bilinmektedir. ${ }^{[11]}$ Uyku apnesi, özellikle HT, DM ve yapısal kalp hastalığı ile ilişkili olduğunda, apne nedeniyle atriyal basınç ve boyutunda artışlar olması veya otonomik değişimler nedeniyle AF için fizyopatolojik bir faktör olarak karşımıza çıkmaktadır. ${ }^{[8]}$ Javaheri ve ark.'nın ${ }^{[12]}$ çalışmasında, kalp yetersizliği ve uyku apnesi olan hastalarda atriyal fibrilasyon, ventriküler aritmiler ve sol ventrikül ejeksiyon fraksiyonunda düşme prevelansı uyku apnesi olmayan KY hastalarından daha yüksek bulunmuştur.

\section{Gereç ve Yöntem}

$\mathrm{Bu}$ araştırma, atriyal fibrilasyon tanısı olan hastalarda obstrüktif uyku apnesi ve uyku kalitesinin belirlenmesi amacıyla tanımlayıcı bir çalışma olarak planlandı ve uygulandı. Araştırmada atriyal fibrilasyon tanısı konulan hastaların obstrüktif uyku apnesi ve uyku kalitesinin nasıldır sorusuna cevap arandı. 
Araştırma, Aralık 2017 ile Mart 2018 tarihleri arasında, İstanbul'da iki üniversite hastanesinin kardiyoloji servislerine yatan, iletişim sorunu olmayan, hekim tarafından AF tanısı konulmuş olan, araştırmaya katılmayı kabul eden 108 hasta ile gerçekleştirildi. Yapılan görüşme için sağlık durumunun uygun olduğu uzman tarafından onaylanan, Türkçe okuyup yazabilen, araştırmaya katılmayı kabul eden hastalar araştırmaya dahil edildi. Araştırmaya katılmaya istekli olmayan, soruları algılamasını ve iletişim kurmasını etkileyecek düzeyde narkotik analjezik kullanan, ciddi mental hastalık tanısı olan, geçici iskemik atak geçiren, bilişsel işlev bozukluğu olan, göğüs ağrısı, dispne ve çarpıntı şikayeti olan hastalar ise araştırmaya dahil edilmedi.

\section{Veri Toplama Araçları:}

Araştırmada kullanılan veri toplama araçları olarak hasta bilgi formu, obstrüktif uyku apnesi semptomları anketi ve uyku kalitesini değerlendirmek için Pittsburgh Uyku Kalitesi İndeksi (PUKI) kullanıldı.

Hasta bilgi formunda, araştırmaya katılan hastaların sosyodemografik özellikleri, sigara, alkol kullanımı, kafeinli içecek tüketimi, hekim tarafından tanısı konulan diğer hastalıkları, reçeteli ilaç kullanımı gibi tanımlayıc bilgilerinin değerlendirildiği 27 madde yer aldı. Araştırmacı tarafından bireylerin beden kitle indeksi (BKi)'nin belirlenmesi için boy ve kilo ölçümü yapıldı.

Bireylerin OSAS semptomlarını değerlendirmek için, literatür doğrultusunda ${ }^{[10,13-15]}$ hazırlanan toplam 11 maddeden oluşan obstrüktif uyku apnesi semptomları anket kullanıldı. Bu anket kullanılarak bireylerin geceleri gürültülü horlamalarının olup olmadığı, varsa sıklığı, başkaları tarafından uyku sırasında soluğun kesilmesinin söylenip söylenmediği, uykudan boğulma hissi ile uyanma durumu, gündüz aşırı uykulu olma, unutkanlık, dikkat azlığı, sinirlilik, özellikle sabahları baş ağrısı şikayeti, sabahları ağız kuruluğu ve boğaz ağrısı, uykuda aşırı terleme ve sık idrar kaçırma, cinsel isteksizlik ve yetersizlik, mide içeriğinin ağza gelmesi (reflü) gibi şikayetlerinin varlığı değerlendirilmektedir.

Pittsburgh Uyku Kalitesi İndeksi son bir aylık sürede uyku kalitesi ve uyku bozukluğunu değerlendiren özbildirim ölçeğidir. PUKI, 1989'da Buysse ve arkadaşları tarafından geliştirilmiş ve yeterli iç tutarlılığa (Cronbach's alfa=0.75), test-tekrar test güvenilirliğine ve geçerliliğe sahip olduğu gösterilmiştir. $^{[17]}$ İndeksin, ülkemizde geçerliği ve güvenilirliği Ağargün ve ark. ${ }^{[18]}$ tarafından yapılmıştır ve Türk toplumuna uygun olduğu (Cronbach alfa $=0.80)$ belirlenmiştir. PUKI'nin değerlendirilmesinde 18 madde puanlamaya katılır. Pittsburgh Uyku Kalitesi Indeksinde toplam puan 0-21 arasında bir değere sahiptir, toplam puanın yüksek oluşu uyku kalitesinin kötü olduğunu göstermektedir. Toplam PUKi puanı, "0-4 puan ise iyi uyku kalitesini”, "5-21 puan ise kötü uyku kalitesini" ifade etmektedir. ${ }^{[18]}$

Araştırmada kullanılan veri toplama formları araştırmacı tarafından yüz yüze görüşülerek ya da bireylerin kendileri tarafından dolduruldu. Formların doldurulması yaklaşık 15 dakika sürdü.

\section{Araştırmanın Etik Yönü}

Araştırmanın uygulanabilmesi için araştırmada kullanılacak olan veri toplama araçları geliştirenlerden ve İstanbul Üniversitesi Cerrahpaşa Tıp Fakültesi Klinik Araştırmalar Etik Kurulu'ndan (09.11.2017 tarih-421498 no) gerekli izinler alındı. Araştırmaya katılmayı kabul eden bireylere Helsinki Bildirgesi doğrultusunda, çalışmanın amacı, veri toplama işleminin nasıl yapılacağı ve ne kadar süreceği “Bilgilendirilmiş Gönüllü Olur Formu” okutularak açıklandı. Araştırmaya katılımları için bilgilendirilmiş sözlü ve yazılı izinleri alındı.

\section{Verilerin Değerlendirilmesi}

Araştırmada elde edilen veriler SPSS 22 software program (IBM Corp., Armonk, NY, USA) programı kullanılarak analiz edildi. Verilerin değerlendirilmesinde tanımlayıc istatistiksel yöntemler olarak sayı, yüzde, ortalama, standart sapma kullanıldı. İki bağımsız grup arasında niceliksel sürekli verilerin karşılaştırılmasında t-testi, ikiden fazla bağımsız grup arasında niceliksel sürekli verilerin karşılaştırılmasında Tek yönlü Anova testi kullanıldı.

\section{Araştırmanın Sınırılıkları}

Araştırmada bazı hastaların veri toplama formlarını doldurmak istememeleri, zaman kısıtlıığı araştırmanın sınırlı yönleridir.

\section{Bulgular}

\section{Bireylerin Tanıtıcı Özellikleri ve Hastalığa iliş̧kin Bulgular}

Araştırmamıza katılan bireylerin \%47.2'sinin erkek, $\% 52.8$ 'inin kadın olduğu, büyük çoğunluğunun 60 yaş ve üzerinde olduğu, \%63.6'sının günde 14 saat çalıştığı, \%38.9'unun ise yalnızca zorunlu intiyaçlarını karşılayabildiği belirlendi (Tablo 1). Araştırmaya katılan bireylerin yaş ortalaması $68.99 \pm 14.02$; BKi ortalaması $27.09 \pm 5.12 \mathrm{~kg} / \mathrm{m}^{2}$ olarak belirlendi (Tablo 1). Bireylerin \%55.6'sının fazla kilolu, \%14.8'inin obez olduğu, \%29.6'sının normal kiloda olduğu tespit edildi. Bireylerin atriyal fibrilasyon tanı süreleri incelendiğinde \%30.6'sı 24 ay ve altı, \%18.5'i 25-48 ay, \%21.3'ü 49-72 ay, \%29.6 72 ay ve üzeri olarak dağıldığı belirlendi. Bireylerin \%58.3'ünün ailesinde atriyal fibrilasyon tanısı bulunduğu, \%41.7'sinin ise ailesinde atriyal fibrilasyon tanısı bulunmadığı saptandı (Tablo 1 ). 
Bireylerin \%13.9'unun haftada 2-3 gün alkol tükettiği, \%48.1'inin sigara kullandığı, \%65.7'sinin günde 3'ten fazla kahve, çay, kafeinli içecek tükettiği, \%83.3'ünün günde 15 gramdan fazla tuz tükettiği belirlendi. Bireylerin \%92.6'sının düzenli reçeteli ilaç kullanma gereksinimi olduğu, bun-

\begin{tabular}{|c|c|c|c|}
\hline Özellikler & (Ort $\pm S S)$ & $\mathbf{n}$ & $\%$ \\
\hline \multicolumn{4}{|l|}{ Cinsiyet } \\
\hline Erkek & & 51 & 47.2 \\
\hline Kadın & & 57 & 52.8 \\
\hline Yaş & $68.99 \pm 14.02$ & & \\
\hline $60 \leq$ & & 20 & 18.5 \\
\hline $61-70$ & & 33 & 30.6 \\
\hline $71-80$ & & 37 & 34.3 \\
\hline $80 \geq$ & & 18 & 16.7 \\
\hline BKi $\left(\mathrm{kg} / \mathrm{m}^{2}\right)$ & $27.09 \pm 5.12$ & & \\
\hline Oksijen satürasyonu (\%) & $95.38 \pm 1.97$ & & \\
\hline Sistolik kan basıncı (mmHg) & $123.63 \pm 17.81$ & & \\
\hline Diastolik kan basıncı (mmHg) & $74.00 \pm 12.37$ & & \\
\hline Kalp hızı (/dk) & $88.94 \pm 12.90$ & & \\
\hline \multicolumn{4}{|l|}{ Çalışma durumu } \\
\hline Evet & & 22 & 20.4 \\
\hline Hayır & & 86 & 79.6 \\
\hline \multicolumn{4}{|l|}{ Meslek } \\
\hline İşçi & & 7 & 31.8 \\
\hline Memur & & 15 & 68.2 \\
\hline \multicolumn{4}{|l|}{ Günlük çalışma saati } \\
\hline 8 & & 14 & 63.6 \\
\hline 9 & & 3 & 13.6 \\
\hline 12 & & 5 & 22.7 \\
\hline \multicolumn{4}{|l|}{ Çalışma vardiyası } \\
\hline Gündüz & & 18 & 81.8 \\
\hline Gece & & 1 & 4.5 \\
\hline Dönüşümlü & & 3 & 13.6 \\
\hline \multicolumn{4}{|l|}{ Gelir düzeyi } \\
\hline $\begin{array}{l}\text { Günlük ihtiyaçlar için rahat } \\
\text { para harcıyorum }\end{array}$ & & 8 & 7.4 \\
\hline Günlük ihtiyaçlarını & & 58 & 53.7 \\
\hline \multicolumn{4}{|l|}{ karşılayabiliyorum } \\
\hline Sadece zorunlu ihtiyaçlarını & & 42 & 38.9 \\
\hline \multicolumn{4}{|l|}{ karşılayabiliyorum } \\
\hline \multicolumn{4}{|l|}{ Atriyal fibrilasyon tanı süresi } \\
\hline $24 \leq$ & & 33 & 30.6 \\
\hline $25-48$ & & 20 & 18.5 \\
\hline $49-72$ & & 23 & 21.3 \\
\hline $72 \geq$ & & 32 & 29.6 \\
\hline Atriyal fibrilasyon tanı süresi (ay) & $62.68 \pm 51.75$ & & \\
\hline \multicolumn{4}{|l|}{$\begin{array}{l}\text { Ailede atriyal fibrilasyon öyküsü } \\
\text { olma durumu }\end{array}$} \\
\hline Evet & & 63 & 58.3 \\
\hline Hayır & & 45 & 41.7 \\
\hline
\end{tabular}

ların da \%98'inin reçeteli ilaçlarını düzenli kullandığı tespit edildi. Egzersiz yapma alışkanlıkları incelendiğinde ise, bireylerin \%99.1'inin egzersiz yapma alışkanlığı olmadığı belirlendi. Araştırmaya katılan bireylerin \%62.0'ında hipertansiyon, \%30.6'sında diyabet olduğu görülürken, $\% 42.6$ 'sında kalp yetersizliği, \%15.7'sinde mide şikayetleri ve \%13'ünde hipertiroidi olduğu belirlendi (Tablo 2).

\section{Tablo 2. Bireylerin uyku apne risk faktörlerinin ve diğer hastalık bilgilerinin dağılımı $(n=108)$

Özellikler $\quad$ n $\quad \%$

Alkol kullanma durumu

Hafta 2-3 Gün

15

Hiç kullanmam

Sigara kullanma durumu

Evet

52

Hayır

Kahve çay kafeinli içecek tüketme sıklığı

Günde 1-2 kez

Günde 3'ten fazla

Günlük tuz alım miktarı 15 gramdan az

15 gramdan fazla

Sakinleştirici veya uyku hapı alma durumu

Evet

Hayır

Düzenli reçeteli ilaç kullanma gerekliliği

Evet

Hayır

$100 \quad 92.6$

Reçeteli ilaçları düzenli kullanma durumu

Evet

Hayır

$98 \quad 98.0$

Büyük bademcik veya geniz eti sorunu olma durumu

Evet

Hayır

0.9

Düzenli egz

Evet

0.9

Hayır

Adet düzensizliği olma durumu*

Evet

3.5

Hayır

$\begin{array}{cc}2 & 3.5 \\ 55 & 96.5\end{array}$

Diğer kronik hastalıklar

Hipertansiyon

62.0

Kalp yetersizliği

$67 \quad 62.0$

Diyabet

Mide şikayetleri

30.6

Hipertiroid

Eklem Sırt ya da kas ağrısı

15.7

Alerjik rinit

Egzama

7.4

Psikolojik bozukluk

*Sadece kadınlar. 


\section{Obstrüktif Uyku Apne Semptomlarına İlişkin Bulgular}

Bireylerin \%73.1'i yeterince uyuduğu halde sabah yorgun uyandığı ve gündüz aşırı uykulu olduğu, \%82.4'ünde unutkanlık, sinirlilik ve dikkat azlığı olduğu, \%38'inin gece horladığı, \%39'unun yorgunsa horladığı, büyük çoğunluğunun (\%68.5) sabahları baş ağrısı şikayeti olduğu, \%69.4'ünün sabahları ağız kuruluğu ve boğaz ağrısı şikayeti olduğu belirlendi (Tablo 3).

Bireylerin uyku kalitesi puan ortalaması $11.315 \pm 3.370$ olarak tespit edildi. Bireylerin uyku kalitesi puanları da yaş değişkenine göre anlamlı farklılık gösterdi ( $F=12.869 ; p<0.05)$. Yaş değişkeni arttıkça uyku kalitesinin azaldığı belirlendi.

\begin{tabular}{|c|c|c|}
\hline Semptom özellikleri & $\mathbf{n}$ & $\%$ \\
\hline \multicolumn{3}{|c|}{ Geceleri gürültülü horlamanız olduğunu söylerler mi? } \\
\hline Evet & 41 & 38.0 \\
\hline Hayır & 67 & 62.0 \\
\hline \multicolumn{3}{|c|}{ Evet ise, hangi sıklıkla horlarsınız? } \\
\hline Hergün & 12 & 29.3 \\
\hline Haftanın 3-4 günü & 13 & 31.7 \\
\hline Yorgunsam bazen & 16 & 39.0 \\
\hline \multicolumn{3}{|c|}{$\begin{array}{l}\text { Uyku sırasında soluğunuzun kesildiği başkaları } \\
\text { tarafından söylendi mi? }\end{array}$} \\
\hline Evet & 20 & 18.5 \\
\hline Hayır & 88 & 81.5 \\
\hline \multicolumn{3}{|c|}{ Uykudan boğulma hissi ile uyandığınız oluyor mu? } \\
\hline Evet & 26 & 24.1 \\
\hline Hayır & 82 & 75.9 \\
\hline \multicolumn{3}{|c|}{$\begin{array}{l}\text { Yeterince uyunmasına rağmen sabah yorgun } \\
\text { uyandığınız, gündüz aşırı uykulu olduğunuz olur mu? }\end{array}$} \\
\hline Evet & 79 & 73.1 \\
\hline Hayır & 29 & 26.9 \\
\hline \multicolumn{3}{|c|}{ Unutkanlık, dikkat azlığı, sinirlilik oluyor mu? } \\
\hline Evet & 89 & 82.4 \\
\hline Hayır & 19 & 17.6 \\
\hline \multicolumn{3}{|c|}{ Özellikle sabahları baş ağrısı şikayeti yaşıyor musunuz? } \\
\hline Evet & 74 & 68.5 \\
\hline Hayır & 34 & 31.5 \\
\hline \multicolumn{3}{|c|}{$\begin{array}{l}\text { Sabahları ağız kuruluğu ve boğaz ağrısı ile uyanma } \\
\text { yaşıyor musunuz? }\end{array}$} \\
\hline Evet & 75 & 69.4 \\
\hline Hayır & 33 & 30.6 \\
\hline \multicolumn{3}{|c|}{ Uykuda aşırı terleme ve sık idrar kaçırma } \\
\hline \multicolumn{3}{|c|}{ yaşıyor musunuz? } \\
\hline Evet & 15 & 13.9 \\
\hline Hayır & 93 & 86.1 \\
\hline \multicolumn{3}{|c|}{ Cinsel isteksizlik ve yetersizlik yaşıyor musunuz? } \\
\hline Evet & 23 & 21.3 \\
\hline Hayır & 85 & 78.7 \\
\hline \multicolumn{3}{|c|}{$\begin{array}{l}\text { Mide içeriğinizin ağzına gelmesi durumunu (reflü) } \\
\text { yaşıyor musunuz? }\end{array}$} \\
\hline Evet & 41 & 38.0 \\
\hline Hayır & 67 & 62.0 \\
\hline
\end{tabular}

Sakinleştirici veya uyku hapı alma durumu ile uyku kalitesi puanı arasında istatistiksel olarak anlamlı bir ilişki belirlendi $(p=0.000)$. Sakinleştirici veya uyku hapı alan bireylerin uyku kalitelerinin kötüleştiği tespit edildi. Bireylerin PUKİ puanlarının obez bireylerde daha yüksek olduğu uyku kalitelerinin diğer BKI gruplarından daha kötü olduğu saptandı $(p>0.05)$ (Tablo 4).

Tablo 4. Pittsburgh uyku kalitesi indeksinin tanımlayıcı özelliklere göre dağılımı $(n=108)$

Demografik özellikler

n Pittsburgh uyku Analiz kalitesi indeksi Ort \pm SS

Cinsiyet

Erkek

Kadın

51

$11.726 \pm 3.073$

$\mathrm{t}=1.200$

Yaş

$60 \leq$

$61-70$

$71-80$

57

$10.947 \pm 3.603$

$\mathrm{p}=0.233$

$80 \geq$

$20 \quad 9.200 \pm 2.505$

$F=12.869$

$33 \quad 10.273 \pm 2.918$

$\mathrm{p}=0.000$

Alkol kullanma durumu

Hafta 2-3 gün

Hiç kullanmam

$11.784 \pm 2.626$

$18 \quad 14.611 \pm 3.806$

Kahve çay kafeinli içecek

tüketme sıklığı

Günde 1-2 kez

Günde 3'ten fazla

$11.703 \pm 3.612$

$\mathrm{t}=0.862$

Sigara kullanma durumu

Evet

71

$11.113 \pm 3.245 \quad p=0.390$

Hayır

$52 \quad 10.942 \pm 3.121 \quad t=-1.108$

Günlük tuz alım miktarı* (gram)

$15 \leq$

$15 \geq$

$15 \quad 11.067 \pm 3.634 \quad t=-0.306$

$93 \quad 11.355 \pm 3.345 \quad p=0.760$

Sakinleştirici veya uyku hapı

alma durumu

Evet

Hayır

24

$14.292 \pm 3.973$

$t=5.547$

BKI Grup*

Normal kilolu

84

$10.464 \pm 2.641 \quad p=0.000$

Fazla kilolu

Obez

$32 \quad 10.875 \pm 3.825 \quad F=1.405$

$60 \quad 11.217 \pm 3.152 \quad p=0.250$

Atriyal fibrilasyon tanı süresi (ay)

$24 \leq$

25-48

49-72

$72 \geq$

$12.563 \pm 3.098$

$10.394 \pm 3.455$

$\mathrm{F}=9.757$

$9.500 \pm 1.821$

$\mathrm{p}=0.000$

Ailede atriyal fibrilasyon öyküsü

olma durumu

$\begin{array}{llll}\text { Evet } & 63 & 11.857 \pm 3.277 & \mathrm{~F}=2.007 \\ \text { Hayır } & 45 & 10.556 \pm 3.388 & \mathrm{p}=0.047\end{array}$

SS: Standart Sapma; F: Tek Yönlü Anova Testi; t: Bağımsız Grup T-Testi; PUKi: Pittsburgh Uyku Kalitesi Indeksi; *BKi: Normal kilolu: $18.5-24.9$ kg $/ \mathrm{m}^{2}$; Fazla kilolu: $25-29.9 \mathrm{~kg} / \mathrm{m}^{2}$; Obez: $<30 \mathrm{~kg} / \mathrm{m}^{2}$. ${ }^{[12]}$ 
Bireylerin PUKI puanlarının atriyal fibrilasyon tanı süresi değişkenine göre anlamlı farklılık gösterdiği saptandı $(F=9.757 ; p=0.000)$. AF tanı süresi 72 ay üzeri olanların PUKi puanlarının diğer tanı sürelerinden yüksek olduğu belirlendi Tanı süresi arttıkça uyku kalitesinin kötüleştiği belirlendi. Ailede atriyal fibrilasyon öyküsü olanların uyku kalitesi puanları, olmayanların PUKI puanlarından yüksek bulundu ( $t=2.007 ; p=0.047$ ). Ailesinde AF öyküsü olan bireylerin uyku kalitelerinin kötü olduğu tespit edildi (Tablo 4).

Diyabet $(t=3.493 ; p=0.002)$, Astım $(t=4.192 ; p=0.000)$ ve Kalp yetersizliği $(t=2.329 ; p=0.022)$ tanısı olanların PUKi puanları, olmayanların uyku kalitesi puanlarından daha yüksek bulundu. Diyabet, Astım ve Kalp yetersizliği tanısı olmasının bireylerin uyku kalitesini kötüleştirdiği belirlendi (Tablo 5).

Yaş ve PUKI arasında zayıf, pozitif yönde $(r=0.421 ; p=0.000)$ ve Oksijen saturasyonu ve PUKI arasında orta, negatif yönde $(r=-0.541 ; p=0.000)$ anlamlı ilişki bulundu. Buna göre araştırmaya katılan bireylerin yaşı arttıkça ve oksijen saturasyonu düzeyi azaldıkça uyku kalitesinin kötüleştiği saptandı (Tablo 6).

\begin{tabular}{|c|c|c|c|}
\hline Demografik Özellikler & $\mathbf{n}$ & $\begin{array}{l}\text { Pittsburgh Uyku } \\
\text { Kalitesi İndeksi } \\
\text { Ort } \pm \text { SS }\end{array}$ & Analiz \\
\hline \multicolumn{4}{|l|}{ Hipertansiyon } \\
\hline Evet & 67 & $11.657 \pm 3.493$ & $t=1.353$ \\
\hline Hayır & 41 & $10.756 \pm 3.121$ & $p=0.179$ \\
\hline \multicolumn{4}{|l|}{ Diyabet } \\
\hline Evet & 33 & $12.939 \pm 3.724$ & $t=3.493$ \\
\hline Hayır & 75 & $10.600 \pm 2.955$ & $p=0.002$ \\
\hline \multicolumn{4}{|l|}{ Astım } \\
\hline Evet & 19 & $14.053 \pm 3.551$ & $\mathrm{t}=4.192$ \\
\hline Hayır & 89 & $10.730 \pm 3.044$ & $p=0.000$ \\
\hline \multicolumn{4}{|l|}{ Mide şikayetleri } \\
\hline Evet & 17 & $11.294 \pm 4.120$ & $t=-0.027$ \\
\hline Hayır & 91 & $11.319 \pm 3.238$ & $p=0.978$ \\
\hline \multicolumn{4}{|l|}{ Eklem sırt ya da kas ağrısı } \\
\hline Evet & 8 & $13.375 \pm 4,406$ & $t=1.816$ \\
\hline Hayır & 100 & $11.150 \pm 3.245$ & $p=0.072$ \\
\hline \multicolumn{4}{|l|}{ Kalp yetersizliği } \\
\hline Evet & 46 & $12.174 \pm 3.427$ & $t=2.329$ \\
\hline Hayır & 62 & $10.677 \pm 3.207$ & $p=0.022$ \\
\hline \multicolumn{4}{|l|}{ Hipertiroidi } \\
\hline Evet & 14 & $11.643 \pm 2.499$ & $t=0.389$ \\
\hline Hayır & 94 & $11.266 \pm 3.489$ & $p=0.698$ \\
\hline
\end{tabular}

SS: Standart sapma; F: Tek yönlü anova testi; t: Bağımsız grup T-Testi; EUÖ: Epworth uykululuk ölçeği; PUKi: Pittsburgh uyku kalitesi indeksi.
Tablo 6. Uyku kalitesi puanları ile tanımlayıcı özellikleri arasındaki korelasyonun değerlendirilmesi $(n=108)$

\begin{tabular}{lcc} 
& \multicolumn{2}{c}{ PUKi } \\
\cline { 2 - 3 } & $\mathbf{r}$ & $\mathbf{p}$ \\
\hline Yaş & $0.421^{* *}$ & 0.000 \\
BKi $\left(\mathrm{kg} / \mathrm{m}^{2}\right.$ ) & 0.144 & 0.137 \\
Oksijen saturasyonu (\%) & $-0.541^{* *}$ & 0.000 \\
Sistolik kan basıncı (mmHg) & 0.168 & 0.082 \\
Diyastolik kan basıncı (mmHg) & $0.293^{* *}$ & 0.002 \\
Kalp hızı (/dk) & $0.342^{* *}$ & 0.000 \\
Atriyal fibrilasyon tanı süresi (ay) & $0.465^{* *}$ & 0.000 \\
\hline **<0.01· r: Korelasyon analizi Puki: Pittsburgh uyku kalitesi indeksi.
\end{tabular}

\section{Tartışma}

\section{Sosyo-Demografik Özelliklere İlişkin Bulgular}

Literatürde AF tanısı olan hastaların \%60'ının kadın olduğu ve AF'nin kadınlarda erkeklere göre 1.5 kat daha fazla olduğu belirtilmiştir. ${ }^{[16]}$ Feinberg ve ark. ${ }^{[2]}$ yaptıkları çalışmalarında erkek kadın oranını 1.7 olarak belirtmişlerdir. Bununla birlikte diğer bir çalışmada da, AF tanılı hastaların \%61'inin erkek olduğu saptanmıştır. ${ }^{[19]}$ Bu çalışmada da literatürle benzerlik göstererek AF tanısı olan kadın cinsiyetin (\%52.8) erkek cinsiyetten (\%47.2) fazla olduğu saptandı (Tablo 1). Literatür incelendiğinde AF prevalansı yaş arttıkça arttığı48 ve yaş ortalamasının 67 olduğu ${ }^{[7]}$ belirtilmektedir. Araştırmada bireylerin yaş ortalamalarının $(68.991 \pm 14.024)$ literatürle benzerlik gösterdiği saptandı (Tablo 1).

Yapılan çalışmalarda genel olarak AF tanısı olan hastalarda koroner arter hastalığını ${ }^{[6,20]}$ ve hipertansiyonun ${ }^{[4]}$ olduğu, ancak çoğunlukla kalp yetersizliği prevalansının çok yüksek ${ }^{[4,16,21]}$ saptanmıştır. Bununla birlikte Dublin ve ark. ${ }^{[22]}$ diyabet tanısı olan hastalarda AF gelişme riskinin \%40 daha fazla olduğunu bulmuştur. Bu çalışmada da literatürle uyumlu olarak bireylerin \%62'sinde hipertansiyon, \%42.6'sında kalp yetersizliği, \%30.6'sında diyabet, \%17.6'sında astım olduğu tespit edildi (Tablo 2). Yıllar boyunca alkol tüketimi AF'nin potansiyel risk faktörü olarak görülmüştür. Kopenhag Şehri Kalp Çalışmasından ${ }^{[8]}$ elde edilen sonuçlarda AF vakalarının \%5'inin alkol tüketimiyle ilgili olduğu belirtilirken, Kodama ve ark'.nın ${ }^{[23]}$ yaptığı meta-analiz çalışmasında ise her gün $10 \mathrm{gr}$ alkol tüketen insanlarda AF gelişme riskinin \%8 oranında arttığı tespit edilmiştir. Jahangir ve ark.'nın ${ }^{[20]} \mathrm{AF}$ tanılı hastalarla yaptıkları çalışmada ise 51 hastadan 39'unun sigara içtiği, 55 hastadan 42'sinin alkol kullandığı ve 63 hastadan 48'inin kafein içeren içecekler tükettiği tespit edilmiştir. Bu çalışmada da literatürle benzer şekilde bireylerin büyük çoğunluğunun (\%65.7) günde 3 bardaktan fazla kafein içeren içecekler tükettiği, bununla birlikte literatürden farklı olarak bireylerin 
büyük çoğunluğunun (\%86.1) alkol kullanmadığı saptandı (Tablo 2).

\section{Uyku Kalitesine İlişkin Bulgular}

Obstrüktif uyku apne sendromunun aralıklı hipoksemi, karbondioksit retansiyonu ve atriyal basınçta ani yükselmelere sebep olduğu, bununla birlikte OSAS varlığının AF'nin gelişimine neden olduğu tespit edilmiştir. ${ }^{[24-26]}$ Atriyal fibrilasyon ve OSAS arasındaki ilişkiyi açıklayan birden fazla mekanizma (Negatif intratorasik basınç, Hipoksemi, Hiperkapni, Otonom sinir sistemi aktivasyonu, İnflamasyon, Hipertansiyon, Sol ventrikül hipertrofisi, Sol atriyal genişleme) bulunmaktadır. Uyku sırasında akut apne olayları AF'nin gelişimi ile doğrudan bağlantılıdır. Bu nedenle, bahsedilen fizyolojik değişiklikler AF ile ilişkilendirilmiştir. ${ }^{[27]}$ Literatür incelendiğinde, AF tanısı olan hastalarda OSAS prevelansının artmış olduğu görülürken, ${ }^{[28]}$ uyku kalitesinin önümüzdeki on yılda önemli ölçüde kötüleşmesi beklenmektedir. ${ }^{[11]} \mathrm{Bu}$ nedenle AF tanılı hastalar ve uyku kaliteleri arasındaki ilişkinin bilinmesi önemlidir.

Mehmet ve ark.'nın ${ }^{[29]} \mathrm{AF}$ tanısı olan hastalarla yaptığı çaIışmada PUKI puan ortalaması $9.4 \pm 4.6$ olarak saptanmış ve AF tanılı bireylerin uyku kalitelerinin kötü olduğu olduğu belirtilmiştir. Bu çalışmada da AF tanılı bireylerin PUKI puan ortalaması $11.31 \pm 3.37$ olarak belirlendi ve uyku kalitelerinin kötüleştiği tespit edildi.

Literatür incelendiğinde, erkeklerdeki uyku kalitesinin kadınlardan daha kötü olduğu belirtilirken, ${ }^{[30]}$ kadınların erkeklerden daha fazla uyku problemi yaşadığı gösterilmektedir. ${ }^{[31]} 5$ Mungan ve ark.'nın ${ }^{[19]}$ AF tanılı hastalarla yaptıkları çalışmada erkek hastaların \%61 oranında OSAS risk faktörlerini taşıdığı belirtilmiş̧ir. Bu çalışmada ise bireylerin PUKI puanları ile cinsiyet değişkeni arasında anlamlı bir ilişki saptanmadı ( $\mathrm{p}=0.233$ ) (Tablo 4).

Mungan ve ark.'nın ${ }^{[19]} \mathrm{AF}$ tanılı hastalarla yaptığı çalışmada hastaların yaş ortalamaları $63.7 \pm 7.6$ olarak bulunmuş ancak yaş değişkeni ve uyku kalitesi arasında anlamlı bir ilişki belirtilmemiştir. Gami ve ark.'nın ${ }^{[13]}$ AF tanılı hastalarla OSAS ve obezite arasındaki ilişkiyi anlatan çalışmalarında ise yaş arttıkça, OSAS semptomlarının arttığı belirtilmiştir. Bu çalışmada da bireylerin yaş ortalamaları $68.99 \pm 14.02$ olarak saptanırken, PUKI puanlarının yaş değişkenine göre anlamlı farklılık gösterdiği tespit edildi. Yaş arttıkça bireylerin uyku kalitelerinin kötüleştiği saptandı (Tablo 4).

Literatürde sigara, alkol ve kafein içeren içeceklerin uyku kalitesini etkilediği bilinmekte ${ }^{[32]}$ ancak uyku kalitesini etkileyen dozun bireysel özelliklere ve genetik faktörlere göre değiştiği belirtilmektedir. ${ }^{[31]}$ Aysan ve ark.'nın ${ }^{[33]}$ uyku kalitesi ve uyku kalitesini etkileyen faktörleri araştırdıkları çalışmada sigaranın içerdiği nikotinden dolayı uyarıcı etkisinin bulunduğu, fazla alkol tüketiminin de REM uykusunu sınırlandırdığı ve merkezi sinir sistemi üzerinde depresan etkisi bulunduğu tespit edilmiş ve kafeinli içecek tüketme durumunun uyku kalitesini bozduğu belirtilmiştir. Bu çalışmada literatürden farklı olarak bireylerin alkol, sigara, kahve ve çay gibi kafeinli içecek tüketme sıklıkları ve uyku puanları arasında ilişki saptanmazken $(p=0.390)$, sakinleştirici veya uyku hapı alma durumu ve uyku puanları arasında anlamlı ilişki tespit edildi ( $p=0.000)$, (Tablo 4). Sakinleştirici veya uyku hapı alan bireylerin uyku kalitelerinin kötü olduğu saptandı. Çalışmada diyabet, astım ve kalp yetersizliği tanısı olan hastaların uyku kalitelerinin, olmayanlardan daha kötü olduğu saptandı (Tablo 5). Literatürde AF tanılı hastalarda var olan kronik hastalıklar ve uyku kalitesi arasındaki ilişkiyi inceleyen çalışmalara rastlanmadı, ancak var olan kronik hastalıkların uyku kalitesini olumsuz etkilediğini gösteren çalışmalar bulunmaktadır. ${ }^{[32]}$

Literatürde nefes darlığı, kalp çarpıntısı ile karakterize olan OSAS'ın AF için risk faktörü olduğu belirtilmiştir. ${ }^{[34]}$ Mungan ve ark.'nın ${ }^{[19]}$ AF tanısı olan hastalarla yaptığı OSAS kriterlerinin araştıııldığı çalışmada, Berlin Soru Anketi kullanılmış ve hastaların \%58'inde OSAS risk faktörü olduğu belirtilmiştir. Bu çalışmada da OSAS semptomlarına bakıldığında, benzer şekilde bireylerin \%38'inin geceleri horlamaları olduğu, \%18.5'inin uyku esnasında soluğunun kesildiği, \%24.1'inin uykudan boğulma hissi ile uyandığı, \%73.1'inin gece yeterince uyumasına rağmen sabah yorgun uyandığı ve gündüz aşırı uykulu olduğu, \%82.4'ünün unutkanlık, dikkat azlığı ve sinirli olduğu, \%68.5'inin sabahları baş ağrısı şikayeti olduğu, \%69.4'ünün sabahları ağız kuruluğu ve boğaz ağrısı yaşadığı, \%13.9'unun uykuda aşırı terleme ve sık idrar kaçırma problemi olduğu, \%38'inin reflü şikayeti olduğu saptandı (Tablo 3).

Obstrüktif uyku apne sendromunun kesin tanılaması için altın standart olarak adlandırılan polisomnografi ile uyku evrelerinin ve fizyolojik parametrelerin ayrıntılı olarak incelenmesinin yanında OSAS'ın tanılanması ve şiddetinin ölçümünde; oksijen saturasyonu, kalp hızı ölçümü de kullanılmaktadır. ${ }^{[35]}$ Obstrüktif uyku apne sendromunda oksijen saturasyonunun düşmesine bağlı en sık görülen semptomlar gürültülü horlama, gündüz uyku hali, gece boğulma hissi ile nefes darlığı içinde uyanma, huzursuz uyku, atipik göğüs ağrısı ve sabah baş ağrısıdır. Bireyde uykusuzluk nedeniyle çabuk sinirlenme, karar verme yeteneğinde azalma gibi değişiklikler görülebilir. ${ }^{[36]}$

Gami ve ark.'nın ${ }^{[37]}$ OSAS ve AF risklerini araştırdıkları çalışmada oksijen saturasyonu ortalaması \%87 olarak tespit edilmiş ve $A F^{\prime} l i$ hastaların oksijen saturasyonlarının düşük olduğu belirtilmiştir. Bayram ve ark.'nın ${ }^{[38]}$ kardiyak aritmi tanısı olan hastalarla yaptığı benzer çalışmada ise oksijen saturasyonu ortalaması $\% 89 \pm 4.3$ olarak tespit edilmiş ve 
OSAS semptomlarının düşük saturasyonda daha fazla olduğu belirtilmiştir. Bu çalışmada bireylerin oksijen saturasyonu ortalaması (Tablo 1) diğer çalışmalardan yüksek bulundu, ancak oksijen saturasyonu ile PUKI puanları arasında literatürle benzer şekilde anlamlı ilişki saptandı $(p=0.000)$, oksijen saturasyonu seviyesi arttıkça bireylerin uyku kalitelerinin iyileştiği tespit edildi (Tablo 6).

\section{Sonuç}

Yaş değişkeni arttıkça bireylerin uyku kalitelerinde bozulma olduğu, çalışan bireylerin uyku kalitelerinin çalışmayan bireylerden daha yüksek olduğu, sakinleştirici veya uyku hapı alan bireylerin uyku kalitelerinin kötü olduğu, tanı süresi arttıkça gün içinde uykululuk durumunun arttığı, uyku kalitesinin kötüleştiği, diyabet tanısı olanların uyku kalitelerinin kötüleştiği belirlendi.

Çalışmadan elde edilen bu sonuçlar doğrultusunda;

- AF tanısı olan hastaların uyku kalitesindeki azalma göz önüne alındığında bu konuda hemşire ve diğer sağlık personeli eğitilerek uyku kalitesini arttırmaya yönelik eğitim programlarının düzenlenmesi,

- Bakım ve tedavi esnasında hastaların uyku kalitelerinin incelenmesi, gerekirse gece uygulanan tedavi planının uyku kalitesini bozmayacak şekilde düzenlenmesi,

- Yaşı bireylerde uyku kalitesinde azalma söz konusu olduğundan, uygun tedavi ve bakımın verilmesi, gerekli olan sağlık desteğinin sağlanması, sosyal ve psikolojik desteğin sağlanarak uyku kalitesinin arttırılması önerilebilir.

\section{Teşekkür}

Çalışma sırasında klinikte destek veren tüm sağlık çalışanlarına ve çalışmaya katılan hastalara ve araştırmada kullanılan ölçekleri geliştiren yazarlara teşekkür ederiz. Ingilizce dil çeviri ve düzenlemeleri için Kalite Tercüme servisine (www.kalitetercüme.com.tr) teşekkür ederiz.

Etik Kurul Onayı: İstanbul Üniversitesi Cerrahpaşa Tıp Fakültesi Klinik Araştırmalar Etik Kurulu. (Tarih: 09.11.2017/Numara: 421498.

Hakem Değerlendirmesi: Dış bağımsız.

Çıkar Çatışması: Yazarlar arasında herhangi bir çıkar çatışması bulunmamaktadır.

Yazarlık Katkıları: Konsept: Ş.Ş., H.U.; Dizayn: Ş.Ş., H.U.; Veri Toplama veya Işleme: S..Ş.; Analiz veya Yorumlama: Ş.Ş., H.U.; Literatür tarama: Ş.Ş., H.U., Yazan: H.U., Ş.Ş.

Finansal Destek: Makale hazırlık ve yazma aşamasında herhangi bir finansal destek alınmamışır. Yazarlar kendi imkanlarını kullanmıştır.

\section{Kaynaklar}

1. Camm AJ, Kirchhof P, Lip GY, Schotten U, Savelieva I, Ernst S, et al. Guidelines for the management of atrial fibrillation: the Task Force for the Management of Atrial Fibrillation of the European Society of Cardiology (ESC). Eur Heart J 2010;31:165.

2. Feinberg WM, Blackshear JL. Prevelance, age distribution, and gender of patients with atrial fibrillation. Analysis and implications. Arch Intern Med 1995;155:469-73.

3. Benjamin EJ, Wolf PA, D'agostino RB, Silbershatz H, Kannel WB, Levy D. Impact of atrial fibrillation on the risk of death: the Framingham Heart Study. Circulation 1998; 98: 946-52.

4. Kannel WB, Benjamin EJ. Current perceptions of the epidemiology of atrial fibrillation. Cardiol Clin 2009;27:13-24.

5. Lloyd-Jones DM, Wang TJ, Leip EP, Larson MG, Levy D, Vasan RS, et al. Lifetime risk for development of atrial fibrillation: the Framingham Heart Study. Circulation 2004;110:1042-6.

6. Ertaş F. Epidemiological approach to the atrial fibrillation patients. Dicle Med J 2013;40: 332-9.

7. Uyarel H, Onat A, Yüksel H, Can G, Ordu S, Dursunoğlu D. Incidence, Prevalence, And Mortality Estimates For Chronic Atrial Fibrillation In Turkish Adults. Türk Kardiyoloji Derneği Arşivi 2008;36:214-22.

8. Menezes AR, Lavie CJ, De Schutter A, Milani RV, O'Keefe J, DiNicolantonio JJ, et al. Lifestyle modification in the prevention and treatment of atrial fibrillation. Progress in Cardiovascular Diseases 2015;58:117-25.

9. Anaszewicz M, Budzyński J. The associations between atrial fibrillation and parameters of nutritional status assessment in the general hospital population a cross-sectional analysis of medical documentation. Kardiol Pol 2017;75:231-9.

10. Aksu T, Illkay E. Obstructive sleep apnea syndrome. [Article in Turkish]. Türk Kardiyoloji Derneği Araştırması 2007; 35:38290.

11. Shukla A, Aizer A, Holmes D, Fowler S, Park DS, Bernstein S, et al. Effect of Obstructive Sleep Apnea Treatment on Atrial Fibrillation Recurrence A Meta-Analysis. JACC Clinical Electrophysiology 2015;1:41-51.

12. Javaheri S, Parker T, Liming JD, Corbett WS, Nishiyama H, Wexler $\mathrm{L}$, et al. Sleep Apnea in 81 Ambulatory Male Patients With Stable Heart Failure Types and Their Prevalences, Consequences, and Presentations. Circulation 1998;97:2154-9.

13. Gami AS, Pressman G, Caples SM, Kanagala R, Gard JJ, Davidson $D E$, et al. Association of atrial fibrillation and obstructive sleep apnea. Circulation 2004;110:364-7.

14. Izci B, Ardic S, Firat H, Şahin A, Altınors M, Karacan I. Reliability and validity studies of the Turkish version of the Epworth Sleepiness Scale. Sleep and Breathing 2008;12:161-8.

15. Leung RS, Huber MA, Rogge T, Maimon N, Chiu KL, Bradley TD. Association between atrial fibrillation and central sleep apnea. Sleep 2005; 28:1543-6.

16. Ertas F, Kaya H, Kaya Z, Bulur S, Kose N, Gül M, et al. Epidemiology of atrial fibrillation in Turkey: preliminary results of the multicenter study. Türk Kardiyol Dern Arşivi 2013; 41:99-104.

17. Buysse DJ, Reynolds CF 3rd, Monk TH, Berman SR, Kupfer DJ. The Pittsburgh Sleep Quality Index : a new instrument for ps- 
ychiatric research and practice. Psychiatry Res 1989;28:193213.

18. Ağargün MY, Çilli AS, Kara H, Bilici M, Telcioğlu M, Semiz ÜB, et al. Epworth Uykululuk Ölçeğinin Geçerliği ve Güvenirliği. Türk Psikiyatri Dergisi 1999;10:261-7.

19. Mungan U, Özeke Ö, Mavioglu L, Ertan C, Karaca IO, Keskin G, et al. The role of the preoperative screening of sleep apnea by Berlin Questionnaire and Epworth Sleepiness Scale for postoperative atrial fibrillation. Heart Lung and Circ 2013;22:38-42.

20. Jahangir A, Lee V, Friedman PA, Trusty JM, Hodge DO, Kopecky $\mathrm{SL}$, et al. Long-term progression and outcomes with aging in patients with lone atrial fibrillation: a 30-year follow-up study. Circulation 2007;115:3050-6.

21. Lubitz SA, Sinner MF, Lunetta KL, Makino S, Pfeufer A, Rahman $\mathrm{R}$, et al. Independent susceptibility markers for atrial fibrillation on chromosome 4q25. Circulation 2010;122:976-84.

22. Dublin S, Glazer NL, Smith NL, Psaty BM, Lumley T, Wiggins KL, et al. Diabetes mellitus, glycemic control, and risk of atrial fibrillation. J Gen Intern Med 2010;25:853-8.

23. Kodama S, Saito K, Tanaka S, Horikawa C, Saito A, Heianza Y, et al. Alcohol consumption and risk of atrial fibrillation: a meta-analysis. J Am Coll Cardiol 2011;57:427-36.

24. van Oosten EM, Hamilton A, Petsikas D, Payne D, Redfearn DP, Zhang $S$, et al. Effect of preoperative obstructive sleep apnea on the frequency of atrial fibrillation after coronary artery bypass grafting. Am J Cardiol 2014;113:919-23.

25. Sin D, Fitzgerald F, Parker JD, Newton G, Floras JS, Bradley TD. Risk factors for central and obstructive sleep apnea in 450 men and women with congestive heart failure. Am J Respir Crit Care Med 1999;160:1101-6.

26. Wolk R, Kara T, Sowers VK. Sleep-disordered breathing and cardiovascular disease. Circulation 2003;108:9-12.

27. Latina J, Estes NA 3rd, Garlitski AC. The Relationship between
Obstructive Sleep Apnea and Atrial Fibrillation: A Complex Interplay. Pulm Med 2013;2013:621736.

28. Patrick R. Obstructive sleep apnea and atrial fibrillation. Fundemantals of sleep technology 2016;25:14-6.

29. Kayrak M, Gul EE, Aribas A, Akilli H, Alibasiç H, Abdulhalikov T, et al. Self-reported sleep quality of patients with atrial fibrillation and the effects of cardioversion on sleep quality. Pacing Clin Electrophysiol 2013;36:823-9.

30. Liu X, Zhao Z, Jia C, Buyssse DJ. Sleep patterns and problems among chinese adolescents. Pediatrics 2008;121:1165-73.

31. Akhlaghi Keshavarz A, Ghalebandi FM. Sleep quality and its correlation with general health in preuniversity students of Karaj. Iranian J Psychiatr Behavioral Science 2009;3:44-9.

32. Gökçe S, Mert H. Kalp Yetmezliği Olan Hastaların Uyku Kalitesi ve İlişkili Etmenlerin İncelenmesi. Hemşirelikte Eğitim ve Araştirma Dergisi 2015;12:113-20.

33. Aysan E, Karaköse S, Zaybak A, İsmailoğlu Günay E. Sleep Quality Among Undregraduate Students and Influencing Factors. Dokuz Eylül Üniversitesi Hemşirelik Yüksekokulu Elektronik Dergisi 2014;7:193-8.

34. McNicholas W, Bonsignore MR. Sleep apnoea as an independent risk factor for cardiovascular disease: current evidence, basic mechanisms and research priorities. Eur Respir J 2007;29:156-78.

35. Lattimore JD, Celermajer DS, Wilcox I. Obstructive sleep apnea and cardiovascular disease. Journal Am Cardiol 2003;41:142937.

36. Köktürk O. Uyku bozuklukları sınıflaması ve ayırıcı tanısı. Tüberküloz ve Toraks Dergisi 2001;49:175-82.

37. Gami AS, Caples SM, Somers VK. Obesity and obstructive sleep apnea. Endocrinol Metab Clin North Am 2003;32:869-94.

38. Bayram N, Çiftçi B. Prevalence of cardiac arrhythmia in obstructive sleep apnea syndrome. Turk J Med Sci 2010;40:843-50. 